Original Article

\title{
Docetaxel-loaded PLGA nanoparticles to increase pharmacological sensitivity in MDA-MB-231 and MCF-7 breast cancer cells
}

\author{
Phuong Tran, Thu Nhan Nguyen, Yeseul Lee, Phan Nhan Tran, and Jeong-Sook Park* \\ College of Pharmacy, Chungnam National University, Daejeon 34134, Korea
}

\author{
ARTICLE INFO \\ Received April 12, 2021 \\ Revised May 4, 2021 \\ Accepted May 17, 2021 \\ *Correspondence \\ Jeong-Sook Park \\ E-mail: eicosa@cnu.ac.kr
}

Key Words

Breast cancer

Cell viability

Docetaxel

Nanoparticles

\begin{abstract}
This study aimed to develop docetaxel (DTX) loaded poly(lactic-coglycolic acid) (PLGA) nanoparticles (DTX-NPs) and to evaluate the different pharmacological sensitivity of NPs to MCF-7 and MDA-MB-231 breast cancer cells. NPs containing DTX or coumarin- 6 were prepared by the nanoprecipitation method using PLGA as a polymer and $d$ - $\alpha$-tocopherol polyethylene glycol 1000 succinate (TPGS) as a surfactant. The physicochemical properties of NPs were characterized. In vitro anticancer effect and cellular uptake were evaluated in breast cancer cells. The particle size and zeta potential of the DTX-NPs were $160.5 \pm 3.0 \mathrm{~nm}$ and $-26.7 \pm 0.46 \mathrm{mV}$, respectively. The encapsulation efficiency and drug loading were $81.3 \pm 1.85 \%$ and 10.6 $\pm 0.24 \%$, respectively. The in vitro release of DTX from the DTX-NPs was sustained at $\mathrm{pH} 7.4$ containing $0.5 \%$ Tween 80 . The viability of MDA-MB-231 and MCF-7 cells with DTX-NPs was $37.5 \pm 0.5 \%$ and $30.3 \pm 1.13 \%$, respectively. The $I_{50}$ values of DTX-NPs were 3.92- and 6.75-fold lower than that of DTX for MDA-MB-231 cells and MCF-7 cells, respectively. The cellular uptake of coumarin-6-loaded PLGA-NPs in MCF-7 cells was significantly higher than that in MDA-MB-231 cells. The pharmacological sensitivity in breast cancer cells was higher on MCF-7 cells than on MDA-MB-231 cells. In conclusion, we successfully developed DTX-NPs that showed a great potential for the controlled release of DTX. DTX-NPs are an effective formulation for improving anticancer effect in breast cancer cells.
\end{abstract}

\section{INTRODUCTION}

Breast cancer occurs when some breast cells begin to grow abnormally and divide more rapidly than healthy cells. These cells accumulate and form a lump or mass. Breast cancer cells can spread to the lymph nodes and other parts of the body. Therefore, the development of a drug with high efficacy in the treatment of breast cancer would play an important role in reducing the death rate of woman with this disease. Many drugs are currently used to treat breast cancer such as doxorubicin [1], gemcitabine [2], paclitaxel [3], docetaxel (DTX) [4], and leuprolide [5]. Among them, DTX is a second-generation taxane approved by the US
Food and Drug Administration (FDA) to treat multiple types of cancers such as breast, non-small cell lung, hormone-refractory prostate cancers, and gastric adenocarcinoma and squamous cell carcinoma of the head and neck [6]. DTX is usually selected as a model drug for the treatment of breast cancer and it acts as a microtubule-stabilizing agent that blocks the cell cycle at the G2/M phase, which inhibits microtubule disassembly during cell-cycle progression, causing cell death. It is designated as biopharmaceutical classification system class IV agent that has poor aqueous solubility and permeability, which reduce its bioavailability, thereby limiting the treatment efficacy. Therefore, the commercial DTX product Taxotere (Sanofi Aventis, Bridgewater, NJ , USA)

\section{(i) $(8$}

This is an Open Access article distributed under the terms of the Creative Commons Attribution Non-Commercial License, which permits unrestricted non-commercial use, distribution, and reproduction in any medium, provided the original work is properly cited. Copyright $\odot$ Korean J Physiol Pharmacol, pISSN 1226-4512, elSSN 2093-3827
Author contributions: P.T. designed the study and wrote the manuscript. T.N.N. performed the HPLC analysis. Y.L. and P.N.T. performed the cell-based assay experiments. J.S.P. supervised and coordinated the study. 
injection was developed to enhance drug solubility [7]. Taxotere is a clear yellow viscous solution, and each milliliter contains 20 mg DTX in $1 \mathrm{ml}$ of polysorbate 80/dehydrated alcohol (50/50, v/ v). It is packaged in single 1-, 4-, and 8-ml vials containing $(20,80$, and $160 \mathrm{mg}$ ) of DTX, respectively. However, the Tween $80 \mathrm{com}$ ponent may cause various side effects such as accumulative fluid retention, acute hypersensitivity reactions, weight gain, pleural or pericardial effusion, and peripheral neuropathy $[8,9]$. Thus, the formulations of nanoparticles (NPs) have been developed to overcome these problems. Nanoformulations have various advantages such as enhanced solubility of hydrophobic drugs, controlled and sustained drug release, improvement of drug half-life in the circulation, and increased the efficacy of cancer therapy [10,11].

Poly(lactic-co-glycolic acid) (PLGA), a copolymer of polylactic acid (PLA) and polyglycolic acid (PGA), is a biocompatible, biodegradable, and nontoxic polymer. PLGA, which is one of the most widely used polymers in drug delivery systems, shows the potential to control sustained release [12-14]. It is approved by the FDA and used in various formulations for drug delivery [15-17] and has also demonstrated tumor targeting $[18,19]$. For NPs, the material used in the surface plays a crucial role in the controlled release, stability, and therapeutic efficacy. In clinical practice, many polymers have been used in the surface of NPs such as poly(ethylene glycol) (PEG) [20,21], methoxy poly(ethylene glycol) (MPEG) [22], 1,2-dilauroyl-sn-glycero-3-phosphocholine (DLPC) [23], and d- $\alpha$ tocopherol polyethylene glycol 1000 succinate (TPGS [vitamin E TPGS]) [23]. TPGS was firstly introduced by Mu and Feng [24] as an emulsifier for NPs of paclitaxel. Recently, TPGS has been widely used to improve the aqueous solubility of hydrophobic drugs [25]. TPGS is formed by the esterification of vitamin E succinate with polyethylene glycol 1000, and its structure consists of a hydrophilic polar head and a lipophilic alkyl tail. Therefore, it can be used to solubilize both hydrophilic and hydrophobic drugs and is widely used to enhance the water solubility of poorly watersoluble drugs. Wang et al. [26] reported that by using TPGS in the surface of PLGA-NPs, the sustained release of drug from NPs can be controlled and thereby enhanced the encapsulation efficiency [27]. In addition, TPGS exhibited toxicity against cancer cells [28] and nontoxicity to normal cells and tissues [29,30], TPGS can enhance the cytotoxicity, cellular uptake [31-33], and the oral bioavailability [34] of the drug, thereby improving therapeutic efficacy of anticancer drugs in the formulation.

In this study, DTX-NPs were prepared by nanoprecipitation method using PLGA as a polymer and TPGS as a surfactant. The optimal percentage of PLGA and TPGS was selected based on the particle size, polydispersity index (PDI) and zeta potential. The morphology was observed using transmission electron microscopy (TEM), whereas differential scanning calorimetry (DSC) and Fourier-transform infrared spectroscopy (FTIR) were used to evaluate the physicochemical interactions. The in vitro release of DTX from the DTX-NPs was analyzed in phosphate-buffered saline (PBS, pH 7.4) containing $0.5 \%(\mathrm{w} / \mathrm{v})$ Tween 80 . The in vitro therapeutic effects of DTX-NPs were evaluated based on anticancer effect and cellular uptake. The differential sensitivity of NPs between MDA-MB-231 and MCF-7 breast cancer cells was also investigated.

\section{METHODS}

\section{Chemicals}

DTX was obtained from Tokyo Chemical Industry Co., Ltd (Tokyo, Japan). TPGS and PLGA were purchased from SigmaAldrich (St. Louis, MO, USA). Acetone and acetonitrile were purchased from Samchun Chemicals (Pyeongtaek, Korea). Breast cancer MDA-MB-231 and MCF-7 cell lines were obtained from the Korean Cell Line Bank. Roswell Park Memorial Institute (RPMI) 1640 medium, fetal bovine serum (FBS), trypsin, and antibiotics were purchased from Hyclone (Logan, UT, USA). Dimethylsulfoxide (DMSO) and 3-(4,5-dimethylthiazol-2-yl)-2,5diphenyltetrazolium bromide (MTT) were purchased from Sigma-Aldrich.

\section{Preparation of DTX-NPs}

DTX-NPs were prepared using the nanoprecipitation method [35] with modifications. Briefly, DTX and PLGA were dissolved in $2 \mathrm{ml}$ acetone, sonicated for $10 \mathrm{~min}$ and then dropped into TPGS solution at a rate of $20 \mathrm{ml} / \mathrm{h}$ using a syringe pump. The solvent was removed by stirring at $500 \mathrm{rpm}$. DTX-NPs were collected by centrifugation at 12,000 rpm for $30 \mathrm{~min}$ and washed three times with distilled water (DW) to remove the residual excipients. The final solid was suspended in $2 \mathrm{ml}$ DW. Coumarin-6-loaded NPs were prepared using same method.

\section{Particle size and zeta potential}

The particle size distribution and surface charge of the DTXNPs were measured in triplicate using Zetasizer Nano-90 and Zetasizer Nano-Z (Malvern Instruments Ltd., Malvern, UK), respectively [15].

\section{Drug encapsulation efficiency (EE) and drug loading (DL)}

The percentage EE and DL of DTX were measured using high performance liquid chromatography (HPLC) with a Capcell Pak C18 column $(150 \times 4.6 \mathrm{~mm}, 5 \mu \mathrm{m}$ particle size; Osaka Soda, Osaka, Japan) [15]. The mobile phase consisted of acetonitrile: water $(70: 30, \mathrm{v} / \mathrm{v})$ and the flow rate was $1 \mathrm{ml} / \mathrm{min}$. The quantity of DTX was determined by measuring the UV absorbance at a wavelength of $232 \mathrm{~nm}$ with injection volume of $20 \mu \mathrm{l}$.

Briefly, the NPs samples were dissolved in acetonitrile and the 
drug content was calculated using a calibration curve (coefficient of determination $\left[R^{2}\right]=0.997$ ). The samples were measured in triplicate and the percentage of EE and DL were calculated as the following equation:

$$
\begin{gathered}
\% E E=\frac{\text { Weight of DTX in nanoparticles }}{\text { Total DTX added }} \times 100 \\
\% D L=\frac{\text { Weight of DTX in nanoparticles }}{\text { Weight of nanoparticles }} \times 100
\end{gathered}
$$

\section{Morphological observation}

The micrograph of the DTX-NPs was evaluated using TEM (model TECNAI G2 F30 S-Twin; FEI, Hillsboro, OR, USA) at an accelerating voltage of $300 \mathrm{kV}$ [15]. The DTX-NPs were placed onto the TEM grid and dried for $24 \mathrm{~h}$. The NPs size was determined using Image software (National Institutes of Health, Bethesda, MD, USA).

\section{DSC and FTIR}

The endothermic melting temperatures of DTX, PLGA, TPGS, and DTX-NPs were obtained using a TGA/DSC1 (Mettler-Toledo $\mathrm{GmbH}$, Greifensee, Switzerland) [36]. The scan range of the samples was from 20 to $250^{\circ} \mathrm{C}$ at a rate of $10^{\circ} \mathrm{C} / \mathrm{min}$.

FTIR (Alpha-P; Brucker Optik, Ettligen, Germany) [36] was used to evaluate the chemical interactions of DTX, PLGA, TPGS, and DTX-NPs at a spectra ranging from 500 to $4,000 \mathrm{~cm}^{-1}$.

\section{In vitro drug release}

The in vitro release of DTX from the NPs was evaluated by the dialysis method [15]. The nanoparticle samples were placed in a dialysis bag (equivalent of $50 \mu \mathrm{g} / \mathrm{ml} \mathrm{DTX)} \mathrm{with} \mathrm{PBS} \mathrm{(pH} \mathrm{7.4)} \mathrm{con-}$ taining $0.5 \%$ Tween 80 and incubated at $37^{\circ} \mathrm{C}$ with gentle shaking in an incubator (LSI-3016A; Daihan Lab Tech Co., Ltd., Namyangju, Korea). At each predetermined time point of $0.5,1,2,4$, 8,12 , and $24 \mathrm{~h}, 1 \mathrm{ml}$ samples were withdrawn and replaced with fresh medium. The amount of DTX was analyzed using HPLC as described above.

\section{In vitro anticancer effect}

MDA-MB-231 and MCF-7 cells were cultured in RPMI 1640 medium with $10 \%(\mathrm{v} / \mathrm{v}) \mathrm{FBS}$ and $1 \%$ antibiotics at $37 \pm 0.5^{\circ} \mathrm{C}$ in an atmosphere containing $5 \% \mathrm{CO}_{2}$. The in vitro anticancer effect was evaluated by MTT assay. Briefly, MDA-MB-231 and MCF-7 cells were seeded in 96-well plates at a density of $1 \times 10^{4}$ cells per well and incubated overnight to allow the cells to adhere. After incubation, the growth medium was removed and cells were treated with DTX and DTX-NPs at $0.2,0.5,5,10$, and $20 \mu \mathrm{g} / \mathrm{ml}$ in the medium. After incubation for $24 \mathrm{~h}$, the cells were washed with PBS, treated with MTT solution $(0.5 \mathrm{mg} / \mathrm{ml}$ in medium) for $3 \mathrm{~h}$, the MTT solution was removed, and then $100 \mu \mathrm{l}$ DMSO was added to dissolve the purple formazan crystals. The absorbance was measured at $570 \mathrm{~nm}$ using a microplate reader (Infinite M200 PRO; Tecan Trading AG, Männedorf, Switzerland). The cell viability was calculated as following equation:

$$
\text { Cell viability (\%) } \frac{\text { Absorbance of treated cells }}{\text { Absorbance of controlled cells }} \times 100
$$

\section{In vitro quantitative cellular uptake of NPs}

In vitro quantitative cellular uptake of NPs was evaluated using microplate reader. Briefly, MDA-MB-231 and MCF-7 cells were seeded in 24 -well plates at a density of $1 \times 10^{5}$ cells per well. After incubation for $24 \mathrm{~h}$, the medium was replaced by coumarin6-loaded PLGA-NPs $(10 \mu \mathrm{g} / \mathrm{ml})$. Fluorescence-based quantitative technique was used to evaluate cellular uptake of NPs. Coumarin- 6 has been used as a hydrophobic fluorescent dye in the in vitro and in vivo monitoring of NPs based delivery system. It is often used as a tracer marker of the PLGA NPs. In this study, coumarin- 6 was selected as a fluorescent dye to mimic the characteristics of DTX to load in the NPs, both DTX and coumarin-6 are insoluble in water. After 0.5-, 1-, 2-, and 4-h incubation, the cells were washed three times with cool PBS and lysed with Trion X-100 (0.5\%, w/v) solution. The fluorescence intensities were measured using a multimode microplate reader (Tecan Trading) at excitation wavelength of $440 \mathrm{~nm}$ and emission wavelength of 520 $\mathrm{nm}$, respectively. Protein was quantified using bicinchoninic acid assay kit (Thermo Fisher Scientific, Waltham, MA, USA), and the fluorescence intensities were normalized to the total protein content.

\section{Stability}

The stability of the NPs for 3 months was evaluated based on particle size, PDI, and zeta potential. The NPs were stored at $4^{\circ} \mathrm{C}$.

\section{Statistical analysis}

The statistical analysis was performed using SigmaPlot 12 (SYSTAT software, Inc., San Jose, CA, USA) using a one-way analysis of variance (ANOVA). All data are expressed as means \pm standard deviations (SD), and a $\mathrm{p}<0.05$ was considered statistically significant.

\section{RESULTS}

\section{Optimization of TPGS and PLGA composition}

PLGA is a copolymer with high biodegradability and biocompatibility that is usually used as a drug delivery carrier in the 
preparation of formulations [12]. It is hydrolyzed to lactic acid and glycolic acid, which can be easily metabolized by the Krebs cycle in the body. To optimize the percentage of TPGS in the test formulations, a PLGA solution $(1 \%, \mathrm{w} / \mathrm{v})$ was prepared in $2 \mathrm{ml}$ acetone, dropped into $35 \mathrm{ml}$ TPGS solution $(0.05,0.1,0.5,1,2$, and $3 \%, \mathrm{w} / \mathrm{v}$ ) using syringe pump at a rate of $20 \mathrm{ml} / \mathrm{h}$ while stirring at $500 \mathrm{rpm}$, and kept overnight for solvent evaporation.

The NPs were collected by centrifugation at 12,000 rpm for 30 min and washed three times with DW. The collected NPs were then dispersed in $2 \mathrm{ml} \mathrm{DW}$. As shown in Table 1, the NPs formulation with 1\% TPGS showed the smallest particle size (155.7 \pm 1.7 $\mathrm{nm})$ with PDI and zeta potential of $0.19 \pm 0.01$ and $-27.3 \pm 0.55$ $\mathrm{mV}$, respectively. Therefore, TPGS (1\%) was selected from the results.

The PLGA was prepared at $1 \%, 2 \%, 3 \%, 5 \%$, and $7 \%(\mathrm{w} / \mathrm{v})$ for screening and optimizing the percentage using the same method used for TPGS, which was used at $1 \%(\mathrm{w} / \mathrm{v})$. As shown in Table 2, $1 \%$ PLGA, which produced the smallest particle size (as above), was considered as the optimal concentration and, thus, was se- lected for NPs preparation.

\section{EE and DL}

DTX-NPs were prepared as described in the methods, and DTX was used at 3, 6, and $9 \mathrm{mg}$ to optimize the amount. As shown in Table 3 , the zeta potential was not significantly different among the formulations, ranging from $-26.7 \pm 0.46$ to $-29.9 \pm$ $1.50 \mathrm{mV}$. The smallest size $(160.5 \pm 3.0 \mathrm{~nm})$ was obtained with 3 mg DTX, whereas the largest size $(205.9 \pm 8.2 \mathrm{~nm})$ was obtained with $9 \mathrm{mg}$ DTX. The EE (\%) decreased from $81.3 \pm 1.85 \%$ to 50.2 $\pm 2.54 \%$ when the amount of DTX increased from 3 to $9 \mathrm{mg}$, respectively. Similarly, the DL (\%) decreased from $10.6 \pm 0.24$ to $5.19 \pm 0.26 \%$ when the amount of DTX increased from 3 to $9 \mathrm{mg}$, respectively. Based on these results, the formulation with $3 \mathrm{mg}$ DTX was selected as the final NPs preparation.

Table 1. Optimization percentage of TPGS $(n=3)$

\begin{tabular}{ccccc}
\hline PLGA $(\%)$ & TPGS $(\%)$ & Particle size $(\mathrm{nm})$ & PDI & Zeta potential $(\mathrm{mV})$ \\
\hline 1 & 0.05 & $260.3 \pm 30$ & $0.31 \pm 0.03$ & $-21.8 \pm 0.20$ \\
1 & 0.1 & $202.2 \pm 1.6$ & $0.20 \pm 0.02$ & $-25.2 \pm 0.67$ \\
1 & 0.5 & $204.2 \pm 3.2$ & $0.21 \pm 0.02$ & $-21.1 \pm 1.27$ \\
1 & 1 & $155.7 \pm 1.7$ & $0.19 \pm 0.01$ & $-27.3 \pm 0.55$ \\
1 & 2 & $204.9 \pm 5.7$ & $0.30 \pm 0.05$ & $-23.6 \pm 0.93$ \\
\hline
\end{tabular}

Values are presented as mean \pm SD. TPGS, $\alpha$-tocopherol polyethylene glycol 1000 succinate; PLGA, poly(lactic-co-glycolic acid); PDI, polydispersity index.

Table 2. Optimization percentage of PLGA in NP $(n=3)$

\begin{tabular}{ccccc}
\hline PLGA $(\%)$ & TPGS $(\%)$ & Particle size $(\mathrm{nm})$ & PDI & Zeta potential $(\mathrm{mV})$ \\
\hline 1 & 1 & $155.7 \pm 1.7$ & $0.19 \pm 0.01$ & $-27.3 \pm 0.55$ \\
2 & 1 & $311.4 \pm 43$ & $0.52 \pm 0.03$ & $-33.0 \pm 1.23$ \\
3 & 1 & $268.3 \pm 63$ & $0.43 \pm 0.02$ & $-33.4 \pm 2.55$ \\
5 & 1 & $307.0 \pm 12$ & $0.29 \pm 0.10$ & $-22.8 \pm 0.56$ \\
7 & 1 & $256.4 \pm 57$ & $0.29 \pm 0.07$ & $-22.8 \pm 0.60$ \\
\hline
\end{tabular}

Values are presented as mean \pm SD. PLGA, poly(lactic-co-glycolic acid); NP, nanoparticle; TPGS, tocopherol polyethylene glycol succinate; PDI, polydispersity index.

Table 3. Physicochemical and encapsulation characteristics of DTX-NP $(n=3)$

\begin{tabular}{cccccc}
\hline DTX $(\mathrm{mg})$ & Particle size $(\mathrm{nm})$ & PDI & Zeta potential $(\mathrm{mV})$ & EE $(\%)$ & DL $(\%)$ \\
\hline 0 & $155.7 \pm 1.7$ & $0.19 \pm 0.012$ & $-27.3 \pm 0.55$ & - & - \\
3 & $160.5 \pm 3.0$ & $0.21 \pm 0.007$ & $-26.7 \pm 0.46$ & $81.3 \pm 1.85$ & $10.6 \pm 0.24$ \\
6 & $174.4 \pm 0.8$ & $0.18 \pm 0.019$ & $-29.9 \pm 1.50$ & $70.2 \pm 1.60$ & $8.09 \pm 0.18$ \\
9 & $205.9 \pm 8.2$ & $0.23 \pm 0.022$ & $-26.9 \pm 0.50$ & $50.2 \pm 2.54$ & $5.19 \pm 0.26$ \\
\hline
\end{tabular}

Values are presented as mean \pm SD. DTX-NP, docetaxel loaded poly(lactic-co-glycolic acid) nanoparticle; PDI, polydispersity index; EE, encapsulation efficiency; DL, drug loading. 


\section{TEM, DSC, and FTIR}

The morphology of the DTX-NPs was analyzed using TEM, and shown in Fig. 1, the NPs morphology was spherical. The TEM images shows the size of NPs is about $100 \mathrm{~nm}$ differed from that of DLS results. It could be explained by the difference in sample preparation for each instrument. Dried samples (dehydrated) were used for TEM, while suspension samples (hydrated) were used for Zetasizer. Thus, the particle sizes of the samples in TEM would be smaller than those in Zetasizer [15].

Fig. 2A shows the DSC thermograms of DTX, PLGA, TPGS, and the DTX-NPs, which were important for evaluating the interactions between DTX and polymers. The melting temperatures of DTX, PLGA, and TPGS were $164.05,53.07$, and $37.92^{\circ} \mathrm{C}$, respectively. Furthermore, the DTX peak did not appear in the DTXNPs formulation; the reason may be because DTX was interacted with the polymer in the formulation or due to a small amount of DTX in the formulation. This will be clarified in the FTIR results.

To evaluate the interactions between DTX and polymers, FTIR was scanned from 500 to $4,000 \mathrm{~cm}^{-1}$. The interactions were indicated by the shifting of peaks from their position in the formulation. The FTIR spectra of DTX, PLGA, TPGS, and DTXNPs are presented in Fig. 2B. From Fig. 2B, the major peaks of pure DTX appeared at $3,464.8 \mathrm{~cm}^{-1}$ for $\mathrm{O}-\mathrm{H}$ stretch, $1,703.2 \mathrm{~cm}^{-1}$ for $\mathrm{C}=\mathrm{O}$ stretch, $1,492.6 \mathrm{~cm}^{-1}$ for benzene ring, $1,370.1 \mathrm{~cm}^{-1}$ for $\mathrm{C}-\mathrm{H}$ stretch, and $1,123.7 \mathrm{~cm}^{-1}$ for $\mathrm{C}-\mathrm{O}$ stretch. This result was similar to the results of Li and Zuo [37] and Kulhari et al. [38]. In the study by Li and Zuo [37], FTIR spectra were obtained at 3,462 $\mathrm{cm}^{-1}$ (O-H stretch), $1,465 \mathrm{~cm}^{-1}$ (benzene ring), and $1,344 \mathrm{~cm}^{-1}$ (C-H stretch). In the study by Kulhari et al. [38], the FTIR spec-

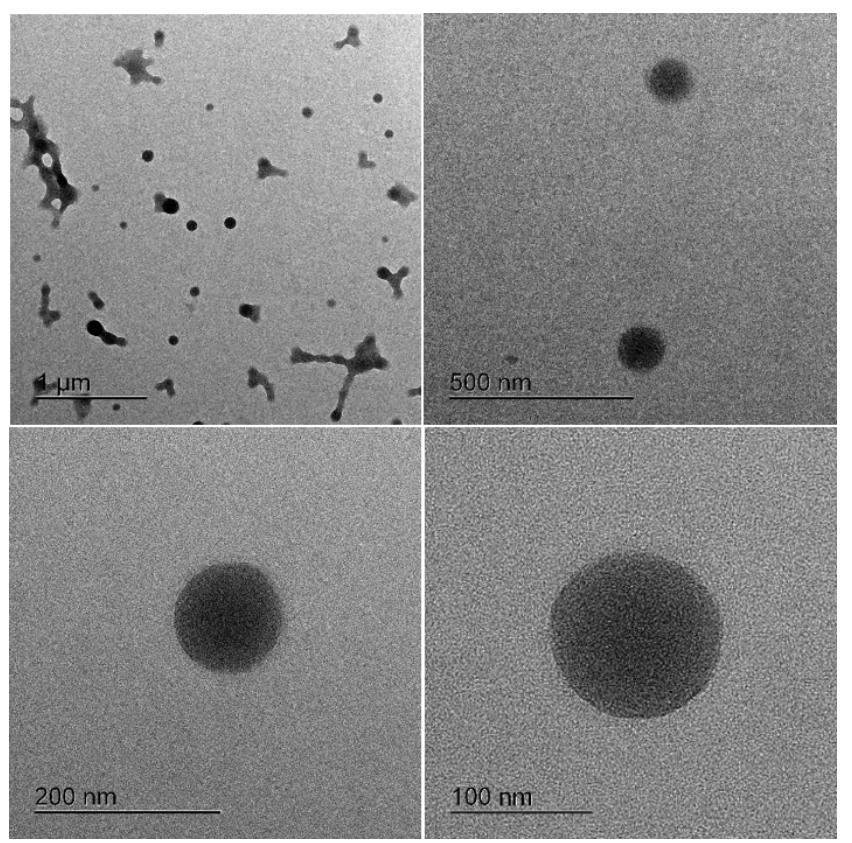

Fig. 1. Transmission electron microscopy of DTX-NPs. DTX-NPs, docetaxel loaded poly(lactic-co-glycolic acid) nanoparticles. tra were obtained at $3,480 \mathrm{~cm}^{-1}(\mathrm{O}-\mathrm{H}$ stretch $), 1,741 \mathrm{~cm}^{-1}(\mathrm{C}=\mathrm{O}$ stretch), and $1,109 \mathrm{~cm}^{-1}$ (C-O stretch). The main peaks of PLGA appeared at $1,752.6 \mathrm{~cm}^{-1}$ in relation to the stretching vibration of $\mathrm{C}=\mathrm{O}$ ester bond, $1,168.3$ for $\mathrm{C}-\mathrm{O}$ stretch, and $1,089.1 \mathrm{~cm}^{-1}$ in relation to the stretching vibration of $\mathrm{C}-\mathrm{O}-\mathrm{C}$. This result was similar to that of a previous study $\left(1,758,1,747 \mathrm{~cm}^{-1}\right.$ for $\mathrm{C}=\mathrm{O}$ ester bond, 1,182 for C-O stretch, and 1,082 and $1,088 \mathrm{~cm}^{-1}$ for C-O-C) [3941]. The major peaks of vitamin E TPGS appeared at $2,884.1 \mathrm{~cm}^{-1}$ for $\mathrm{O}-\mathrm{H}$ stretch, $1,737.3 \mathrm{~cm}^{-1}$ for $\mathrm{C}=\mathrm{O}$ stretch, $1,463.9 \mathrm{~cm}^{-1}$ for benzene ring, $1,342.1 \mathrm{~cm}^{-1}$ for $\mathrm{C}-\mathrm{H}$ stretch, and $1,103.6$ for $\mathrm{C}-\mathrm{O}$

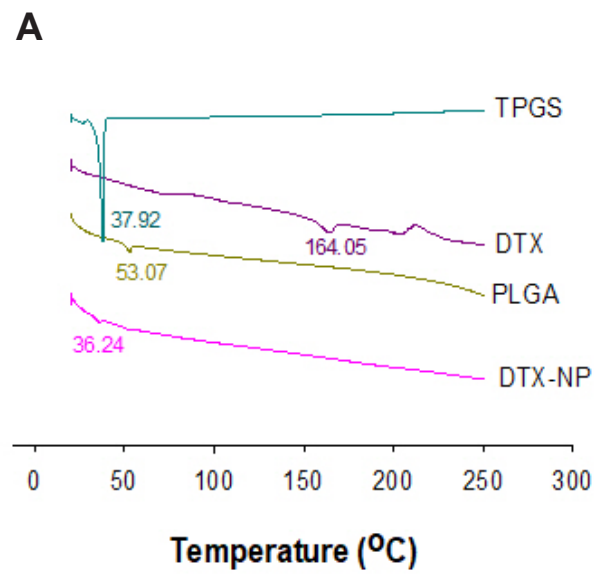

B
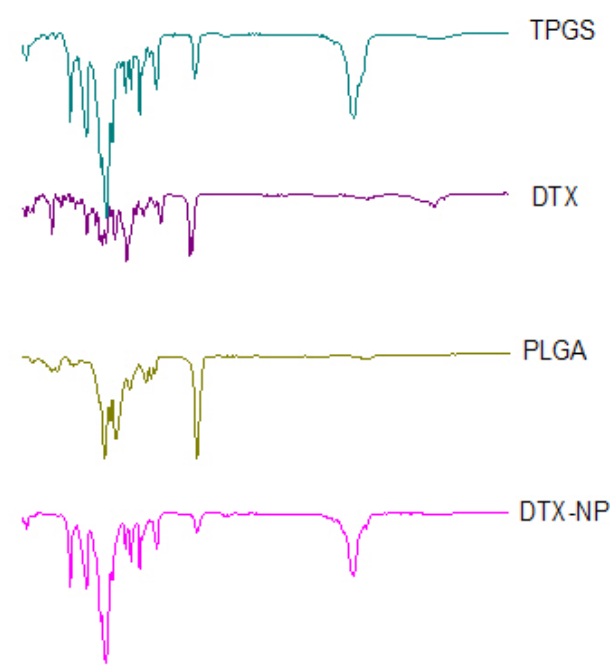

$500 \quad 100015002000250030003500 \quad 4000$

\section{Wave number $\left(\mathrm{cm}^{-1}\right)$}

Fig. 2. DSC (A) and FTIR spectra (B) of DTX, PLGA, TPGS, and DTXNPs. DSC, differential scanning calorimetry; FTIR, Fourier-transform infrared spectroscopy; DTX, docetaxel; PLGA, poly(lactic-co-glycolic acid); TPGS, tocopherol polyethylene glycol succinate; DTX-NPs, docetaxel loaded poly(lactic-co-glycolic acid) nanoparticles. 
stretch. The main peaks of DTX-NPs appeared at $2,880.3 \mathrm{~cm}^{-1}$ for $\mathrm{C}-\mathrm{H}$ stretch, $1,762.9 \mathrm{~cm}^{-1}$ for $\mathrm{C}=\mathrm{O}$ stretch, $1,468.1 \mathrm{~cm}^{-1}$ for benzene ring, $1,341.8 \mathrm{~cm}^{-1}$ for $\mathrm{O}-\mathrm{H}$ stretch, and $1,097.8 \mathrm{~cm}^{-1}$ for $\mathrm{C}-\mathrm{O}$ stretch.

The O-H stretching peak did not appear in DTX-NPs. The peak of $\mathrm{C}=\mathrm{O}$ stretching shifted from $1,703.2 \mathrm{~cm}^{-1}$ (DTX) to $1,762.9$ $\mathrm{cm}^{-1}$ (DTX-NPs). The peak of the benzene ring stretching shifted from $1,492.6 \mathrm{~cm}^{-1}$ (DTX) to $1,468.1 \mathrm{~cm}^{-1}$ (DTX-NPs). The peak of C-H stretching shifted from $1,370.1 \mathrm{~cm}^{-1}$ (DTX) to $1,341.8 \mathrm{~cm}^{-1}$ (DTX-NPs). The peak of C-O stretching shifted from 1,123.7 $\mathrm{cm}^{-1}$ (DTX) to $1,097.8 \mathrm{~cm}^{-1}$ (DTX-NPs). These shifts in the peaks indicate the interactions between DTX and the polymer in NPs formulations.

\section{In vitro drug release}

The in vitro drug release was studied for $24 \mathrm{~h}$ using the dialysis method. Because of the poor solubility of DTX in the buffer solution, $0.5 \%(\mathrm{w} / \mathrm{v})$ Tween 80 was used to simulate sink conditions. The amount of DTX released from the NPs was measured using HPLC, and the in vitro release profiles are shown in Fig. 3. Pure DTX was quickly released and reached a cumulative release of $92.1 \pm 0.88 \%$ after $12 \mathrm{~h}$, whereas DTX showed a slower release profile from DTX-NPs $(32.9 \pm 4.96 \%)$ after $12 \mathrm{~h}$, which was approximately 2.8 times slower than that of the pure DTX [15].

\section{In vitro anticancer effect and cellular uptake of NPs}

The anticancer effect of DTX-NPs at concentrations of $0.2,0.5$, 5,10 , and $20 \mu \mathrm{g} / \mathrm{ml}$ was evaluated in MDA-MB-231 and MCF-7 breast cancer cells by determining the percentage of cell viability using the MTT assay. The results are shown in Fig. 4, the percentage of viable cells was reduced with increasing concentrations of DTX, and the DTX-NPs exhibited a higher anticancer effect

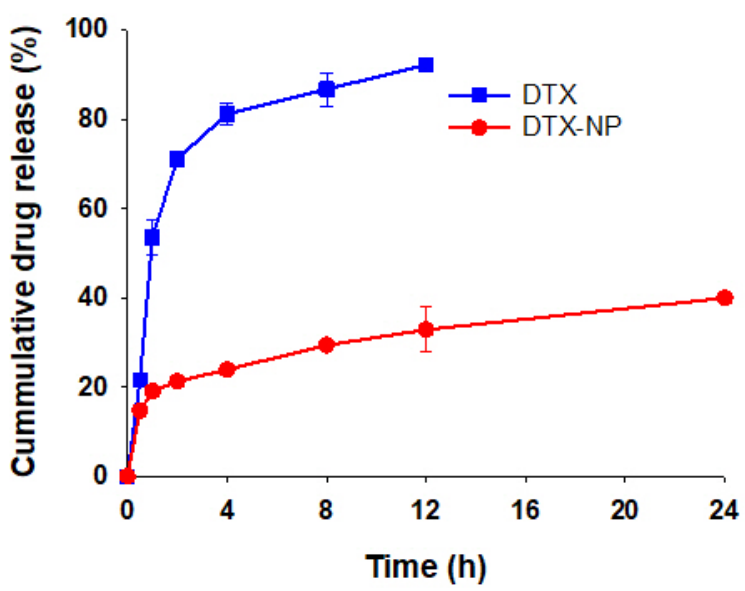

Fig. 3. In vitro dissolution release of DTX-NPs in PBS pH 7.4 containing $\mathbf{0 . 5 \%}$ Tween $\mathbf{8 0}$. Results were represented as mean $\pm \mathrm{SD}(n=3)$. DTX, docetaxel; DTX-NPs, docetaxel loaded poly(lactic-co-glycolic acid) nanoparticles; PBS, phosphate-buffered saline. at all concentrations than that of the pure DTX for both MDAMB-231 and MCF-7 cells (Fig. 4A, B, respectively). The enhanced anticancer effect of DTX-NPs may be due to sustained release of DTX from NPs. The viability of the DTX-treated MDA-MB-231 cells decreased from $89.8 \pm 0.62 \%$ to $50.5 \pm 3.24 \%$, whereas that of cells treated with DTX-NPs decreased from $72.2 \pm 3.96 \%$ to 37.5 $\pm 0.50 \%$ by increasing the concentrations of DTX from 0.2 to 20 $\mu \mathrm{g} / \mathrm{ml}$, respectively. For the pure DTX-treated MCF-7 cells, the viability decreased from $91.5 \pm 10.4 \%$ to $48.1 \pm 0.17 \%$, whereas the DTX-NPs-treated cells showed a decrease in viability from 71.2 $\pm 0.57 \%$ to $30.3 \pm 1.13 \%$ with an increase in DTX concentration from 0.2 to $20 \mu \mathrm{g} / \mathrm{ml}$, respectively. The anticancer effect of DTXNPs in MDA-MB-231 and MCF-7 cells was 1.26- and 1.34-fold higher, respectively, than that of pure DTX at $20 \mu \mathrm{g} / \mathrm{ml}$. Although the change in the percentage of cell viability after $24 \mathrm{~h}$ is similar between MDA-MB-231 cells and MCF-7 cells, the sensitivity of

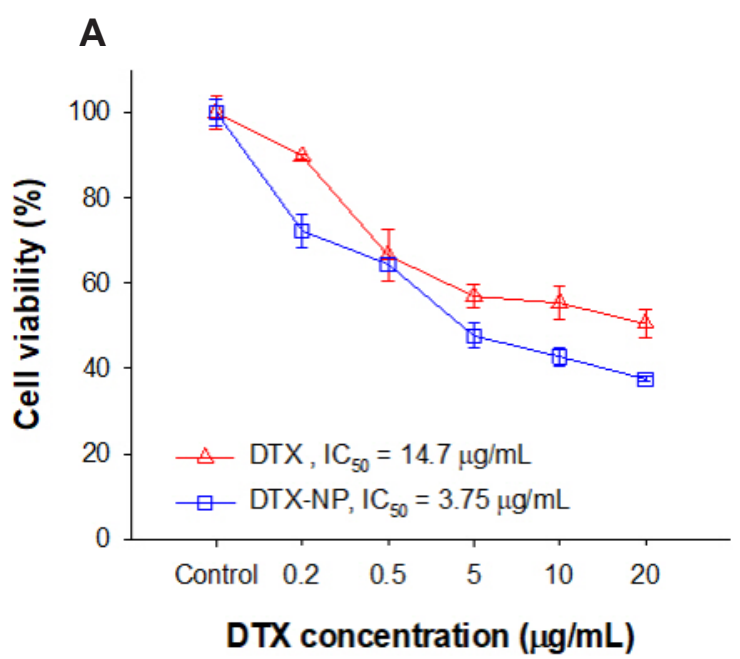

$$
\text { B }
$$

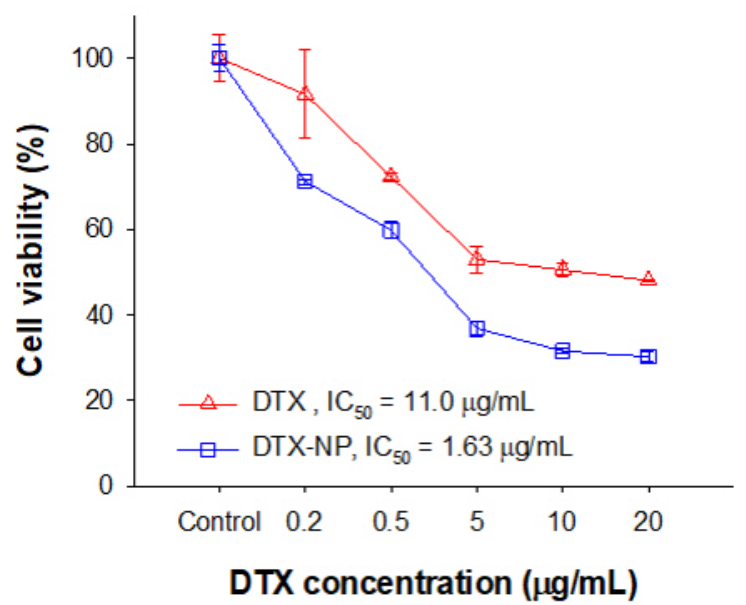

Fig. 4. In vitro anticancer effect of DTX-NPs in MDA-MB-231 (A) and MCF-7 (B) cells. Results were represented as mean \pm SD $(n=3)$. DTX, docetaxel; DTX-NPs, docetaxel loaded poly(lactic-co-glycolic acid) nanoparticles; $I C_{50}$, half-maximal inhibitory concentration. 
DTX-NPs was different in MDA-MD-231 cells and MCF-7 cells. As the results, the anticancer effect of DTX-NPs in MCF-7 cells was 1.12 -fold higher than that in MDA-MB-231 cells at $20 \mu \mathrm{g} /$ $\mathrm{ml}$. In this study, the different sensitivity of DTX-NPs to MCF7 and MDA-MB-231 cells was more clarified in the result of halfmaximal inhibitory concentration $\left(\mathrm{IC}_{50}\right)$, as below.

The different sensitivity of DTX-NPs to MDA-MB-231 and MCF-7 cells became more evident in the results of $\mathrm{IC}_{50}$. $\mathrm{IC}_{50}$ was measured using GraphPad Prism 5 software (San Diego, CA, USA) and the result was shown in Table 4. For MDA-MB-231 cells, the $\mathrm{IC}_{50}$ values were $14.7 \pm 1.14$ and $3.75 \pm 1.03 \mu \mathrm{g} / \mathrm{ml}$ for DTX and DTX-NPs, respectively. The $\mathrm{IC}_{50}$ values of DTX-NPs was 3.92-fold lower than that of DTX. For MCF-7 cells, the $\mathrm{IC}_{50}$ values were $11.0 \pm 1.08$ and $1.63 \pm 1.03 \mu \mathrm{g} / \mathrm{ml}$ for DTX and DTXNPs, respectively. The $\mathrm{IC}_{50}$ values of DTX-NPs was 6.75 -fold lower than that of DTX. These results showed that the DTX-NPs formulation improved the anticancer effect of DTX. In addition, the $\mathrm{IC}_{50}$ of DTX-NPs in MCF-7 cells was 2.3-fold lower than that in MBA-MB-231 cells, indicating that the DTX-NPs formulation was more sensitive in MCF-7 cells than MDA-MB-231 cells.

The cellular uptake results of coumarin-6-loaded PLGA-NPs in MDA-MB-231 and MCF-7 cells are shown in Fig. 5. The results show that cellular uptake increased as the incubation time increased. The cellular uptake in MDA-MB-231 cells was 221.3 $\pm 19.7,239.3 \pm 54.7,539.9 \pm 33.5$, and $763.7 \pm 42.5$ (fluorescent intensity/ $\mu$ g protein) at $0.5,1,2$, and $4 \mathrm{~h}$, respectively, whereas corresponding values in MCF-7 cells were 253.3 \pm 72.5, $273.7 \pm 175.9$, $695.5 \pm 78.3$, and $898.7 \pm 204.1$ (fluorescent intensity/ $\mu$ g protein), respectively. The cellular uptake of the NPs in MCF-7 cells was higher than that in MDA-MB-231 cells at all-time points. At 0.5, 1,2 , and $4 \mathrm{~h}$, the cellular uptake of NPs in MCF-7 cells was 1.1-, 1.1-, 1.3-, and 1.2-fold higher than that in MDA-MB-231 cells. In addition, the cellular uptake of coumarin-6-loaded PLGA-NPs in MCF-7 cells was significantly higher $(\mathrm{p}<0.05)$ than that in MDAMB-231 cells at 2 and $4 \mathrm{~h}$. These results indicate that the cellular uptake of the NPs in MDA-MB-231 and MCF-7 breast cancer cells increased with time and was significantly $(\mathrm{p}<0.05)$ higher in MCF-7 cells than in MDA-MB-231 cells after 2 and $4 \mathrm{~h}$.

\section{Stability}

The stability of a formulation played an important role in clinical therapy of anticancer drugs [42]. In this study, the stabil- ity of the DTX-NPs sample was analyzed after storage at $4^{\circ} \mathrm{C}$ by measuring the particle size, PDI, and zeta potential every 2 weeks for 3 months, and the results are shown in Fig. 6. The results are expressed as means \pm SD. The results illustrated in Fig. 6 show that all three factors of the DTX-NPs were stable with a very small change over 3 months. The initial particle size of the DTX-NPs was $160 \pm 3.0 \mathrm{~nm}$, and it remained stable at $166.9 \pm 3.8 \mathrm{~nm}$ after 3 months. The zeta potential changed slightly after the first 2 weeks (from $-26.7 \pm 0.46 \mathrm{mV}$ to $-22.8 \pm 0.46 \mathrm{mV}$ ) and then remained stable during the storage time $(-21.6 \pm 1.3 \mathrm{mV}$ after 3 months) [43]. This indicates the good stability of the sample.

\section{DISCUSSION}

In this study, the NPs were prepared with $1 \%$ of PLGA and $1 \%$ of TPGS. Based on the Table 3, the particle size of the NPs increased with increasing amount of DTX; the increase in particle size may have been due to the increase of drug amount in the nanoformulation [44]. In a previous study, the particle size increased with an increase in the drug amount from $0.25 \%$ to $1 \%(\mathrm{w} / \mathrm{v})$, whereas the EE decreased along the same drug amount range [45]. In fact, only a fixed amount of drug can be incorporated with a fixed amount of polymer in the formulation. Increasing the amount of drug resulted in a more viscous dispersed phase, which increased the particle size. The EE (\%) and DL (\%) decreased with the increase of DTX amount. The EE decreased with increasing drug content, which may be due to the increased drug diffusion to the external phase caused by a greater flux at the higher drug content during the NPs formation process $[45,46]$. Therefore, the final DTX-NPs were prepared with $3 \mathrm{mg}$ of DTX, $1 \%$ PLGA, and $1 \%$ TPGS.

The release profile of pure DTX was very fast, whereas DTX showed sustained release from the NPs formulations. The sustained release behavior may be due to the slow degradation of the PLGA polymer and strong interaction between the drug and polymer [47,48]. Therefore, the DTX-NPs showed sustained release, which could be clinically beneficial. Generally, a high or repeat dose is required to obtain the desired effect in the treatment of cancer, resulting in many side effects because of the toxicity of anticancer drugs. Therefore, the dose and frequency of drug administration could be reduced by preparing DTX-NPs with sustained release. Moreover, the maintenance of drugs in the

Table 4. Half-maximal inhibitory concentration $\left(\mathrm{IC}_{50}\right)$ of DTX and DTX-NP in breast cancer cells $(\mathbf{n}=\mathbf{3})$

\begin{tabular}{clcr}
\hline Cell lines & Groups & $\mathrm{IC}_{50}(\mu \mathrm{g} / \mathrm{ml})$ & 95\% Confidence intervals \\
\hline MDA-MB-231 & DTX & $14.7 \pm 1.14$ & $7.59-28.4$ \\
MCF-7 & DTX-NP & $3.75 \pm 1.03$ & $3.20-4.39$ \\
& DTX & $11.0 \pm 1.08$ & $7.40-16.4$ \\
& DTX-NP & $1.63 \pm 1.03$ & $1.41-1.89$ \\
\hline
\end{tabular}

Values are presented as mean \pm SD. DTX, docetaxel; DTX-NP, docetaxel loaded poly(lactic-co-glycolic acid) nanoparticles. 


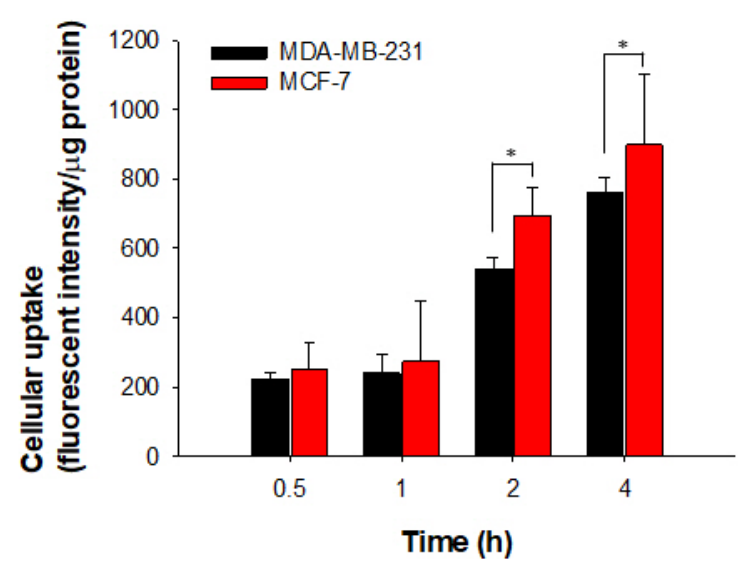

Fig. 5. Quantitative cellular uptake of coumarin-6-loaded PLGANPs in breast cancer cells (MDA-MB-231 and MCF-7 cells). Results were expressed as mean \pm SD $(n=3)$. PLGA-NPs, poly(lactic-co-glycolic acid) nanoparticles. $\left.p<0.05{ }^{*}\right)$ indicated statistical significance.

body after administration of DTX-NPs could improve the drug pharmacokinetics following both oral and parenteral administration.

The in vitro anticancer effect results indicated that the anticancer effect of DTX-NPs in MDA-MB-231 and MCF-7 breast cancer cells was higher than that of pure DTX. Moreover, the anticancer effect of DTX-NPs was higher in MCF-7 cells than in MDAMB-231 cells, suggesting the sensitivity of DTX-NPs was higher in MCF-7 cells than MDA-MB-231 cells. The different sensitivity of NPs to MCF-7 and MDA-MB-231 cells may due to the differences in the expression of breast cancer-related proteins. In practice, MCF-7 and MDA-MB-231 are the most common cell lines used in breast cancer research. They belong to subtypes of metastatic lobular carcinoma and originated from pleural effusions. However, there are difference between two cell lines. MCF-7 is a hormone receptor (estrogen, ER; progesterone, $\mathrm{PR}$ ) positive breast cancer cell. It is widely studied model for hormone-dependent human breast cancer. MDA-MB-231 is a triple-negative breast cancer cell (lack of ER and PR). MDA-MB-231 cell line provides a model for human breast cancer, which exhibits an estrogen-independent state and does not express estrogen receptor. The lack of ER and PR in MDA-MB-231 is the key for the different sensitivity between MCF-7 and MDA-MB-231. Besides, another difference between MCF-7 and MDA-MB-231 is MCF-7 represents for luminal epithelial phenotype while MDA-MB-231 represents for mesenchymal phenotype. In addition, the different sensitivity of these two cell lines MCF-7 and MDA-MB-231 depends on the drug used.

The cellular uptake of the NPs was evaluated by loading coumarin- 6 into the PLGA-NPs, which were then incubated with MCF-7 and MDA-MB-231 breast cancer cells. The ratio of the fluorescence intensities to total protein content was calculated. The cellular uptake of NPs was confirmed by coumarin-6-loaded NPs and it is believed that of DTX-loaded NPs was also increased
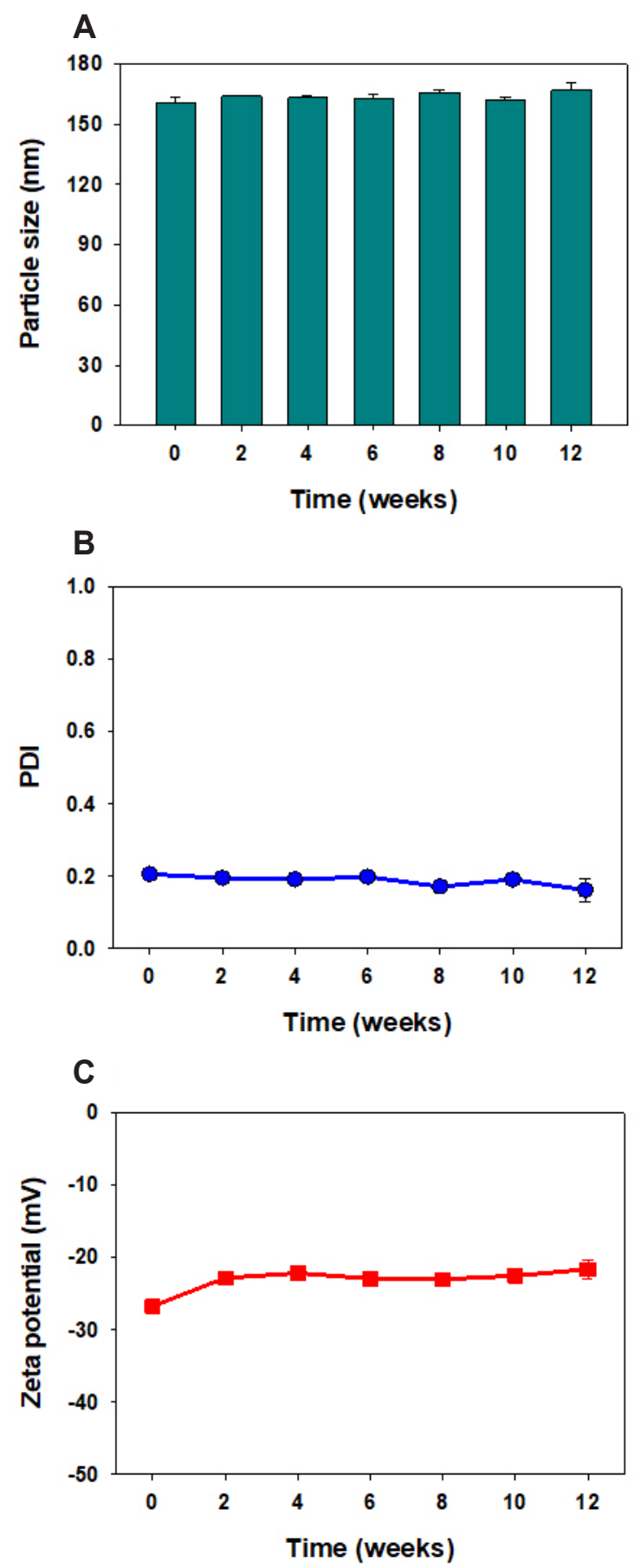

Fig. 6. Stability of DTX-NPs after 3 months: (A) Particle size, (B) Polydispersity index (PDI), and (C) Zeta potential. Results were represented as mean \pm SD $(n=3)$. DTX-NPs, docetaxel loaded poly(lacticco-glycolic acid) nanoparticles.

because we already confirmed the in vitro anticancer effect of DTX-loaded NPs. The enhanced cellular uptake of DTX-NPs in breast cancer cells improved intracellular accumulation of DTX and increased cytotoxic effect of DTX. DTX-NPs showed more cytotoxic and higher cellular uptake than DTX alone. Furthermore, the sensitivity of DTX-NPs to MDA-MB-231 cells and 
MCF-7 cells was different. The sensitivity of DTX-NPs in MCF-7 cells was higher than that of MDA-MB-231 cells.

In conclusion, DTX-NPs were successfully formulated using PLGA as the polymer and TPGS as the surfactant with high encapsulation, low PDI, and negative zeta potential. The TEM results revealed that the NPs had a spherical morphology. The in vitro release analyses showed the sustained release of DTX from the DTX-NPs, which also exhibited a higher anticancer effect on breast cancer cells than that of the pure DTX. As a result of visual experiments, the quantitative cellular uptake of coumarin6-loaded PLGA-NPs was higher than DTX alone. The anticancer effect and cellular uptake results showed the different sensitivity of DTX-NPs between MDA-MB-231 cells and MCF-7 cells. The sensitivity of DTX-NPs on MCF-7 cells was significantly higher than on MDA-MB-231 cells. Moreover, the DTX-NPs showed stability of particle size, PDI, and zeta potential after 3 months. In conclusion, our study indicates that the DTX-NPs formulation is a potential candidate for breast cancer therapy with different sensitivity between MDA-MB-231 cells and MCF-7 cells. To confirm these findings, further studies are needed in various cancer cell lines and in vivo.

\section{ACKNOWLEDGEMENTS}

This work was supported by the National Research Foundation of Korea (NRF) grant funded by the Korea government (MSIT) (NRF-2020R1F1A1075127 and NRF-2021R1A2C1011176).

\section{CONFLICTS OF INTEREST}

The authors declare no conflicts of interest.

\section{REFERENCES}

1. Lovitt CJ, Shelper TB, Avery VM. Doxorubicin resistance in breast cancer cells is mediated by extracellular matrix proteins. BMC Cancer. 2018;18:41.

2. Xie Z, Zhang Y, Jin C, Fu D. Gemcitabine-based chemotherapy as a viable option for treatment of advanced breast cancer patients: a meta-analysis and literature review. Oncotarget. 2017;9:7148-7161.

3. Martín M. nab-Paclitaxel dose and schedule in breast cancer. Breast Cancer Res. 2015;17:81.

4. Sorolla A, Wang E, Clemons TD, Evans CW, Plani-Lam JH, Golden E, Dessauvagie B, Redfern AD, Swaminathan-Iyer K, Blancafort P. Triple-hit therapeutic approach for triple negative breast cancers using docetaxel nanoparticles, EN1-iPeps and RGD peptides. Nanomedicine. 2019;20:102003.

5. Kendzierski DC, Schneider BP, Kiel PJ. Efficacy of different leuprolide administration schedules in premenopausal breast cancer: a retrospective review. Clin Breast Cancer. 2018;18:e939-e942.
6. U.S. Food and Drug Administration. MedWatch: The FDA safety information and adverse event reporting program [Internet]. Silver Spring (MD): U.S. Food and Drug Administration, 1996 [cited 2020 May 12]. Available from: www.fda.gov/medwatch.

7. U.S. Food and Drug Administration. Taxotere ${ }^{\circledR} 2015$ [Internet]. Silver Spring (MD): U.S. Food and Drug Administration, 2015 [cited 2020 Jul 17]. Available from: https://www.accessdata.fda.gov/ drugsatfda_docs/nda/2015/020449orig1s075.pdf.

8. Gaucher G, Marchessault RH, Leroux JC. Polyester-based micelles and nanoparticles for the parenteral delivery of taxanes. J Control Release. 2010;143:2-12.

9. Engels FK, Mathot RA, Verweij J. Alternative drug formulations of docetaxel: a review. Anticancer Drugs. 2007;18:95-103.

10. Mi Y, Guo Y, Feng SS. Nanomedicine for multimodality treatment of cancer. Nanomedicine (Lond). 2012;7:1791-1794.

11. Kutty RV, Feng SS. Cetuximab conjugated vitamin E TPGS micelles for targeted delivery of docetaxel for treatment of triple negative breast cancers. Biomaterials. 2013;34:10160-10171.

12. Makadia HK, Siegel SJ. Poly lactic-co-glycolic acid (PLGA) as biodegradable controlled drug delivery carrier. Polymers (Basel). 2011;3:1377-1397.

13. Blasi P. Poly(lactic acid)/poly(lactic-co-glycolic acid)-based microparticles: an overview. J Pharm Investig. 2019;49:337-346.

14. Elmowafy EM, Tiboni M, Soliman ME. Biocompatibility, biodegradation and biomedical applications of poly(lactic acid)/poly(lacticco-glycolic acid) micro and nanoparticles. J Pharm Investig. 2019;49: 347-380.

15. Choi JS, Jang WS, Park JS. Comparison of adsorption and conjugation of Herceptin on poly(lactic-co-glycolic acid) nanoparticles effect on cell internalization in breast cancer cells. Mater Sci Eng C Mater Biol Appl. 2018;92:496-507.

16. Gao J, Liu J, Xie F, Lu Y, Yin C, Shen X. Co-delivery of docetaxel and salinomycin to target both breast cancer cells and stem cells by PLGA/TPGS nanoparticles. Int J Nanomedicine. 2019;14:9199-9216.

17. Prabhuraj RS, Bomb K, Srivastava R, Bandyopadhyaya R. Selection of superior targeting ligands using PEGylated PLGA nanoparticles for delivery of curcumin in the treatment of triple-negative breast cancer cells. J Drug Deliv Sci Technol. 2020;57:101722.

18. Danhier F, Ansorena E, Silva JM, Coco R, Le Breton A, Préat V. PLGA-based nanoparticles: an overview of biomedical applications. J Control Release. 2012;161:505-522.

19. Berthet M, Gauthier Y, Lacroix C, Verrier B, Monge C. Nanoparticle-based dressing: the future of wound treatment? Trends Biotechnol. 2017;35:770-784.

20. Chambon P, Chen L, Furzeland S, Atkins D, Weaver JVM, Adams DJ. Poly(N-isopropylacrylamide) branched polymernanoparticles. Polym Chem. 2011;2:941-949.

21. Perinelli DR, Cespi M, Bonacucina G, Palmieri GF. PEGylated polylactide (PLA) and poly (lactic-co-glycolic acid) (PLGA) copolymers for the design of drug delivery systems. J Pharm Investig. 2019;49:443-458.

22. Zhang Y, Hou J, Qian C, Song L, Guo S. Taxol-loaded nanoparticles with methoxy poly(ethylene glycol)-b-poly( $\varepsilon$-caprolactone) as a novel additive in the outer aqueous phase. J Appl Polym Sci. 2011;121:2386-2393.

23. Akhtar N, Ahad A, Khar RK, Jaggi M, Aqil M, Iqbal Z, Ahmad FJ, Talegaonkar S. The emerging role of P-glycoprotein inhibitors in 
drug delivery: a patent review. Expert Opin Ther Pat. 2011;21:561576.

24. Mu L, Feng SS. Vitamin E TPGS used as emulsifier in the solvent evaporation/extraction technique for fabrication of polymeric nanospheres for controlled release of paclitaxel (Taxol). J Control Release. 2002;80:129-144.

25. Guo Y, Luo J, Tan S, Otieno BO, Zhang Z. The applications of Vitamin E TPGS in drug delivery. Eur J Pharm Sci. 2013;49:175-186.

26. Wang G, Yu B, Wu Y, Huang B, Yuan Y, Liu CS. Controlled preparation and antitumor efficacy of vitamin E TPGS-functionalized PLGA nanoparticles for delivery of paclitaxel. Int J Pharm. 2013;446:24-33.

27. Zhang Z, Lee SH, Gan CW, Feng SS. In vitro and in vivo investigation on PLA-TPGS nanoparticles for controlled and sustained small molecule chemotherapy. Pharm Res. 2008;25:1925-1935.

28. Shieh MJ, Hsu CY, Huang LY, Chen HY, Huang FH, Lai PS. Reversal of doxorubicin-resistance by multifunctional nanoparticles in MCF-7/ADR cells. J Control Release. 2011;152:418-425.

29. Yang C, Wu T, Qi Y, Zhang Z. Recent advances in the application of vitamin E TPGS for drug delivery. Theranostics. 2018;8:464-485.

30. Neuzil J, Tomasetti M, Mellick AS, Alleva R, Salvatore BA, Birringer M, Fariss MW. Vitamin E analogues: a new class of inducers of apoptosis with selective anti-cancer effects. Curr Cancer Drug Targets. 2004;4:355-372.

31. Win KY, Feng SS. Effects of particle size and surface coating on cellular uptake of polymeric nanoparticles for oral delivery of anticancer drugs. Biomaterials. 2005;26:2713-2722.

32. Gan CW, Feng SS. Transferrin-conjugated nanoparticles of poly(lactide)-D-alpha-tocopheryl polyethylene glycol succinate diblock copolymer for targeted drug delivery across the blood-brain barrier. Biomaterials. 2010;31:7748-7757.

33. Zhang Z, Feng SS. Nanoparticles of poly(lactide)/vitamin E TPGS copolymer for cancer chemotherapy: synthesis, formulation, characterization and in vitro drug release. Biomaterials. 2006;27:262270.

34. Varma MV, Panchagnula R. Enhanced oral paclitaxel absorption with vitamin E-TPGS: effect on solubility and permeability in vitro, in situ and in vivo. Eur J Pharm Sci. 2005;25:445-453.

35. Noori Koopaei M, Khoshayand MR, Mostafavi SH, Amini M, Khorramizadeh MR, Jeddi Tehrani M, Atyabi F, Dinarvand R. Docetaxel loaded PEG-PLGA nanoparticles: optimized drug loading, in-vitro cytotoxicity and in-vivo antitumor effect. Iran J Pharm Res. 2014;13:819-833.

36. Choi JS, Kwon SH, Lee SE, Jang WS, Byeon JC, Jeong HM, Park JS. Use of acidifier and solubilizer in tadalafil solid dispersion to enhance the in vitro dissolution and oral bioavailability in rats. Int $J$
Pharm. 2017;526:77-87.

37. Li A, Zuo L. Construction of anti-EpCAM drug-loaded immunomagnetic balls and its application in diagnosis of breast cancer. Nano Life. 2019;9:1940006.

38. Kulhari H, Pooja D, Shrivastava S, Telukutala SR, Barui AK, Patra CR, Naidu Vegi GM, Adams DJ, Sistla R. Cyclic-RGDfK peptide conjugated succinoyl-TPGS nanomicelles for targeted delivery of docetaxel to integrin receptor over-expressing angiogenic tumours. Nanomedicine. 2015;11:1511-1520.

39. Jiang P, Yu D, Zhang W, Mao Z, Gao C. Influence of bovine serum albumin coated poly(lactic-co-glycolic acid) particles on differentiation of mesenchymal stem cells. RSC Adv. 2015;5:40924-40931.

40. Wang Y, Li P, Kong L. Chitosan-modified PLGA nanoparticles with versatile surface for improved drug delivery. AAPS PharmSciTech. 2013;14:585-592.

41. de Souza Pietra RCC, Cruz RC, Melo CN, Rodrigues LB, Santos PC, Bretz GPM, Soares BM, de Sousa GR, Ferreira MVL, Cisalpino PS, Magalhães PP, de Macêdo Farias L, Pinotti M. Evaluation of polymeric PLGA nanoparticles conjugated to curcumin for use in aPDT. Braz J Pharm Sci. 2017;53:e16043.

42. Jang MH, Kim CH, Yoon HY, Sung SW, Goh MS, Lee ES, Shin DJ, Choi YW. Steric stabilization of RIPL peptide-conjugated liposomes and in vitro assessment. J Pharm Investig. 2019;49:115-125.

43. Choi JS, Park JS. Design and evaluation of the anticancer activity of paclitaxel-loaded anisotropic-poly(lactic-co-glycolic acid) nanoparticles with PEGylated chitosan surface modifications. Int J Biol Macromol. 2020;162:1064-1075.

44. Sharma N, Madan P, Lin S. Effect of process and formulation variables on the preparation of parenteral paclitaxel-loaded biodegradable polymeric nanoparticles: a co-surfactant study. Asian J Pharm Sci. 2016;11:404-416.

45. Krishnamachari Y, Madan P, Lin S. Development of $\mathrm{pH}$ - and timedependent oral microparticles to optimize budesonide delivery to ileum and colon. Int J Pharm. 2007;338:238-247.

46. Gabor F, Ertl B, Wirth M, Mallinger R. Ketoprofen-poly(D,L-lacticco-glycolic acid) microspheres: influence of manufacturing parameters and type of polymer on the release characteristics. J Microencapsul. 1999;16:1-12.

47. Rafiei P, Haddadi A. Docetaxel-loaded PLGA and PLGA-PEG nanoparticles for intravenous application: pharmacokinetics and biodistribution profile. Int J Nanomedicine. 2017;12:935-947.

48. Qureshi OS, Kim HS, Zeb A, Choi JS, Kim HS, Kwon JE, Kim MS, Kang JH, Ryou C, Park JS, Kim JK. Sustained release docetaxel-incorporated lipid nanoparticles with improved pharmacokinetics for oral and parenteral administration. J Microencapsul. 2017;34:250261. 